\title{
ABILITY CONSIDERATION OF F-K AND SPAC METHODS USING MICROTREMORS IN NORTH OF IRAN
}

\author{
M. Esfahanizadeh ${ }^{1}$, M. Davoodi ${ }^{2}$, E. Haghshenas ${ }^{3}$, M. K. Jafari ${ }^{4}$
}

\begin{abstract}
In this research a set of microtremor array measuring was performed in site of Shaghayegh ParkTehran with goal of evaluating the shear wave velocity (Vs) profile for the layers close to the surface. The F$\mathrm{K}$ array processing and SPAC techniques are used and the results are compared with other data particularly a 180 meter depth. The data in different times are compared with the real Vs profile. The results show the SPAC process is more suitable in comparison to the $\mathrm{f}-\mathrm{k}$ method. SPAC technique shows similar results to the f-k method when few data stations are used for measuring with small dimensions. The dispersion curves obtained through processing each of subarrays were extracted and then compared with the dispersion curve obtained through shear wave velocity profile of Down Hole. At the end our results are compared with previous works and strength points are mentioned. This comparison indicated better efficiency of orthogonal arrays in the mentioned site. The assessment showed better efficiency of orthogonal arrays in the used site.

Key words: Shear wave velocity, Microtremor, F-K method, SPAC method.
\end{abstract}

\section{INTRODUCTION}

Precise assessment of the S-wave velocity of the sub-layers has specific significance for the sites evaluation and other fields in earthquake study. One of the important points in estimating local site effects is the knowledge of basin structure: geometry of the interface between the filling and the bedrock, nature and thickness of the sediments. In most of the cities and urban areas of the world are founded on soft the soil composition is prone to amplify seismic waves. One of the most important environmental properties of the soil is shear-wave velocity. Nowadays by means of non destructive methods, shear-wave velocity of the subsurface layers of the earth are determined. By using microtremor in a single station or more to measure shear wave velocity of the earth layers many researchers and engineers are interested recently to evaluate different sites. For the low cost and lesser time consuming, compared to other Vs study methods such as boring and direct measurements, this method is now acceptable. Microtremor measurement is a very helpful method for obtaining ground dynamic character, together with the main period and the site amplification factor using $\mathrm{H} / \mathrm{V}$ spectral ratios.

The solitary site microtremor method is based on using the H/V technique, introduced by Nakamura in 1989. This technique gives accurately the natural frequency of sedimentary deposits. Though, it has some margins in estimating the Vs profile due to its simultaneous dependency on sediment thickness and shear wave velocity. The shape of used sites are triangular, circular, semi-circular, orthogonal, of course most usual ones for array arrangement can be used. In the urban areas, use of each form depends on spatial limitations on organization of site stations and circular and semi-circular arrays mostly are used (Cara 2008).

The microtremor array methods are based on properties of surface wave and are as the alternative technique, which could give the Vs profile of a site. There are two main classes of array processing methods, the Frequency-Wave number (F-K) and the Spatial Autocorrelation (SPAC) methods.

\footnotetext{
${ }^{1}$ Ph.D Student, Department of Civil Engineering, Science and Research Branch, Islamic Azad University, Tehran

${ }^{2}$ Assistant Prof., International Institute of Earthquake Engineering and Seismology, Tehran. I.R. Iran

${ }^{3}$ Assistant Prof. of IIEES, Tehran. I.R. Iran

${ }^{4}$ Prof. of IIEES, Tehran. I.R. Iran
} 
In this paper using some direct geotechnical/geophysical tests, the real Vs profile of the studied site has been determined. Later Vs profile will be calculated using F-K and SPAC methods. At the end the results will be compared with real Vs profile in order to explore ability of the microtremor array technique in estimating shear wave structure of subsurface (Cornou 2004).

\section{EVALUATION AND PROCESS OF DATA}

Figure 1 shows the location of studied site and the arrangement of stations in different arrays processed during this study. District-wide study 51 degrees, and approximately two hundred meters from the beach geographic in the location 36 and 57 degrees is provided.

The northern part of the Caspian Sea up to the side of the narrow beam, low-lying area covered hills alluvial and wind gone and most of the Earth's surface is covered with sediments in city Kelarabad the northern foothills of the Alborz Mountains is centrally located. Plain north of the city, is plain with a slope of South to north, the east-west by the heights and fall sessions are divided into various sections.

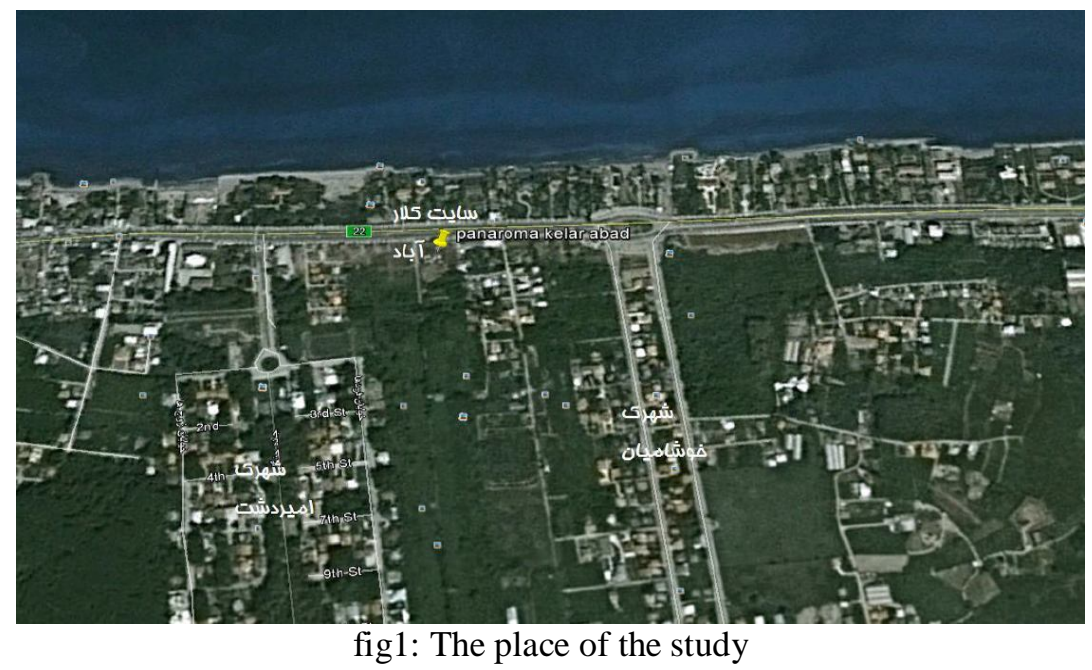

\subsection{Geotechnical and seismic site Kelarabad}

Geotechnical and geophysical studies in order to identify and geotechnical studies at the site had done. The location of the four holes are 73, 63, 43, 33 meter in different parts of the studied area with method of Wash Boring. During drilling operations impact test at different depths done. Test impact and influence common standard test to measure density especially in geotechnical investigations and assessment of granular soils consistency in fine-grained soils sticky are considered.

Subsurface soil conditions, obtained by the four holes, indicates that layers of soil in the study area is mainly sandy soils with clay, mud and sand is coarse particles. Geophysical studies to estimate the dynamic parameters of subsurface layers of elastic modulus and modulus shear wave velocity profile for dynamic analysis and accurate determination of compression and shear took place (Davoodi 2008).

\subsection{Microtremor array registration on Kelarabad}

For the purposes of this study, the effect of the number and spacing of receivers in performance delivery methods, different patterns in different distances with different numbers of receptors and were used on this site, the results evaluations with shear wave velocity profiles obtained from boreholes and test and layering within compared well array includes three general categories triangular geometry, orthogonal and was a semi-circle, because of the limited number of devices Seismograph 15 sets so-called semi-circular array of large and small semicircle divided into two modes. Each one contains a dozen of its installations array of subsets that are introduced subsequently (Gardner 1994). 


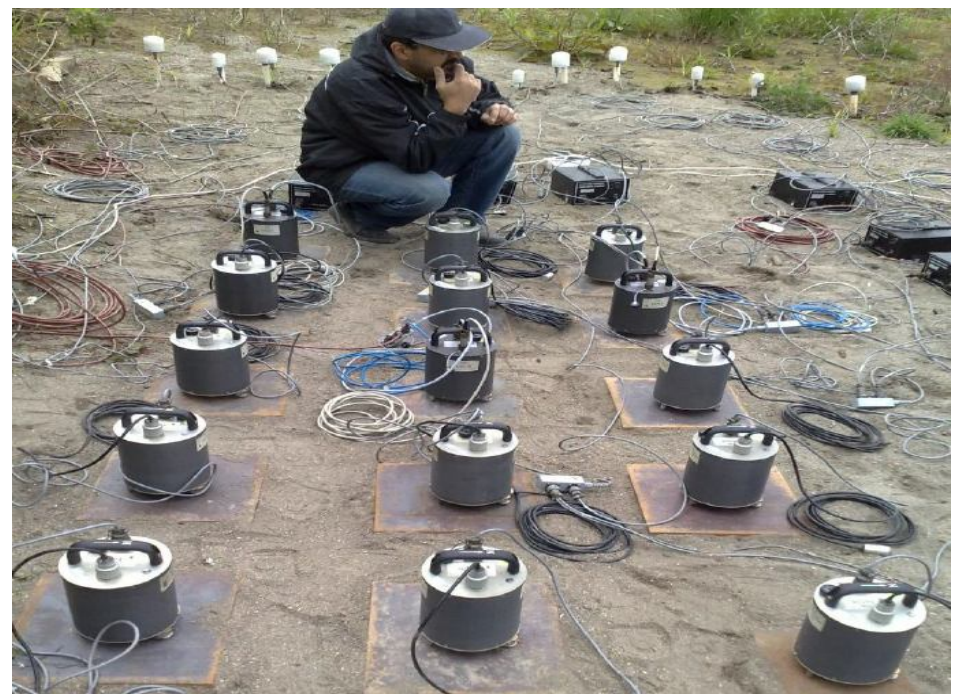

fig 2: Installing devices for calibration and comparison

Collecting microtremor data on 21 to 23 March of 2009 is done; recording of the 13 hours each day often began $1 \mathrm{pm}$ and lasted $10 \mathrm{am}$ the next morning. It also uses a database of domestic and international networks of non-earthquake accelerometer in a radius of $333 \mathrm{~km}$ study area during data recording. The sampling frequency is $133 \mathrm{symbol} / \mathrm{second}$ (Nakamura 1989).

\subsection{Micrometer measurement}

Field measurements made by both methods, an array of measurement and measurement for single point. Measurement data in Kelarabad in the number 35 spots by a single point in five point method are recorded. The proposed method is only recorded data to consider Takes.

In Figure 5 Microtremor recording devices in the Kelarabad are shown (Paolucci 1999).

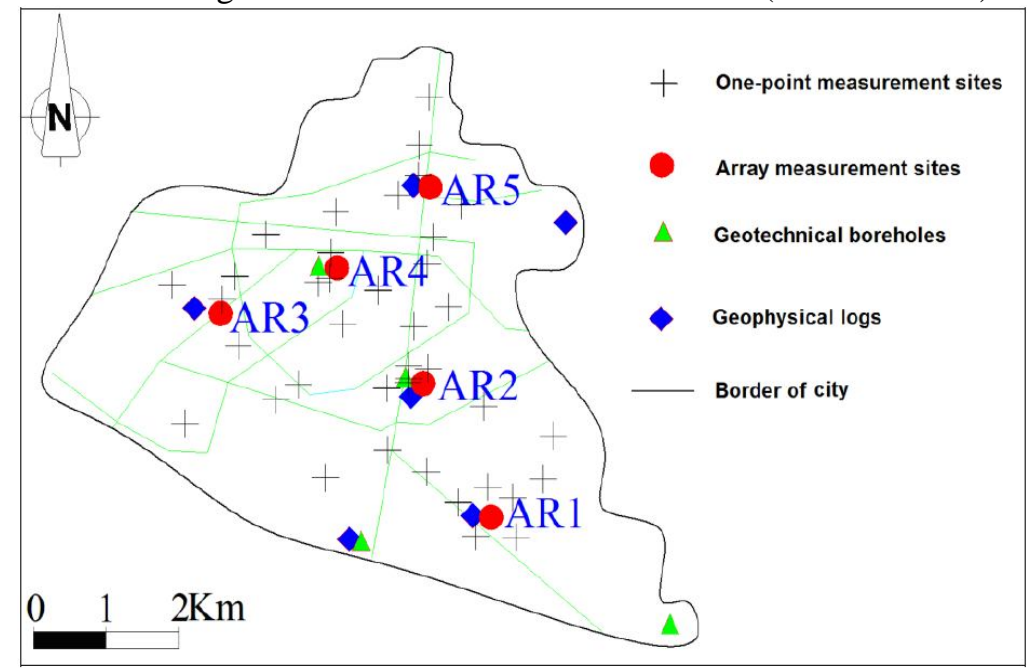

fig 3: location of the Microtremor recording devices in Kelarabad

Microtremor recording device is a digital speedometer. The natural frequency of $0.5 \mathrm{~Hz}$, respectively.

This device has mild earth tremors harvest rate. Different sampling intervals are desired. The equipment used in this method has a number of sensors three-component velocity of reinforcements, low pass filters, analog to digital converters and portable computer is formed(Park 2004). In Figure 2 the arrangement of the sensors in place it has been shown. Figure 4 shows the locations of the micrometers in the site. As can be seen in this particular case, five three-component sensor or single component vertical circle and spaced at equal distances from one another on ground level are located. Also a scanner Component is located in the center of the circle. That is generally 8 or 18 components moving simultaneously be recorded. Movement Analog 
measured by the sensor and is strengthening Low-pass filter and a bunch of digital data 2348 or 4386 stored point (Poormirzaee 1997).

Table 1: geometrical specifications of the array are used in Kelarabad

\begin{tabular}{|c|c|c|c|c|}
\hline$D_{\operatorname{Min}}(\mathrm{m})$ & $\mathrm{D}_{\text {Max }}(\mathrm{m})$ & Dmax/Dmin & Dmean & Sensor No. \\
\hline 5 & 8.6 & 1.72 & 6.8 & 4 \\
\hline 10 & 17.3 & 1.73 & 13.65 & 4 \\
\hline 20 & 34.6 & 1.73 & 27.3 & 4 \\
\hline 40 & 69.3 & 1.73 & 54.65 & 7 \\
\hline 5 & 17.3 & 3.46 & 11.15 & 7 \\
\hline 10 & 34.6 & 3.46 & 42.23 & 7 \\
\hline 20 & 69.3 & 3.46 & 19.8 & 7 \\
\hline 5 & 34.6 & 6.92 & 37.15 & 7 \\
\hline 5 & 69.3 & 13.86 & 39.65 & 10 \\
\hline 10 & 69.3 & 6.93 & 39.65 & 19.8 \\
\hline 5 & 69.3 & 6.93 & 37.15 & 13 \\
\hline 5 & 34.6 & 6.92 & & 7 \\
\hline
\end{tabular}

Since the sources of error in measuring mainly due to configuration errors, lack of balance receptors and the artificial annoying vibrations near the receiver, is, we tried to relative calibration instruments, check full installation instructions seismic and protect them against rainfall, before the original records of errors reduce to a minimum(Betting 2001).

Also, due to the international road near the site to the north, the traffic and pedestrians and vehicles are registered and in addition, because of the changing conditions of climate in northern of Iran, the climate air was collected at harvest time if it affects the data that is Microtremor study. A relationship in which Phase velocity than the wavelength or frequency changes, the property is called dispersion. Property distribution Specific surface waves on the surface of a layered environment are released and the waves are not observed volume. A curve that changes the phase velocity of the wave length or frequency show, called dispersion curve (Nourozi 2013).

Area is divided into five areas as AR1, AR2, AR, 3, AR4 and AR5 whereon AR1 denotes the oldest and grading through to AR5 which denotes the most recent formed alluvium.

Aki in 1965 settled a method to realize a phase-velocity dispersion curve from the microtremors data by a seismic array. He found the spatial cross-correlation coefficient as a function of frequency for a given interstation distance, $r$, and angular frequency, $\omega, \rho(r, \omega)$, averaged over many different azimuths, $\tau$, can be written as (Berberian 1985).

$$
\rho(\mathrm{r}, \omega)=\frac{1}{2 \pi \Phi(r=0, \omega) \int_{0}^{2 \pi} \Phi(r, \theta, \omega) d \theta}=J_{0}\left(\frac{r \omega}{c}\right)
$$

where $\rho(r=0, \omega)$ is the average autocorrelation function at the centre of the array, $\varphi(r, \theta, \omega)$ is the crosscorrelation function between the record at a site and the record gained at the site, $\mathrm{c}$, is the phase velocity at frequency $\omega$ at the site, and $\mathrm{J}_{0}$ is the Bessel function of first kind and order zero. The power spectrum at frequency $f$ and vector wavenumber $k$ for an array of $N$ is

$$
P(f, k)=\left[\sum_{i, j=1}^{N} \varphi_{i j}^{-1}(f) \exp \left(i \vec{k} \cdot \overrightarrow{r_{i j}}\right)\right]^{-1}
$$

where

$N=$ number of sensors.

$\phi_{i j}(f)=$ cross-power spectrum between $i_{t h}$ and $j_{t h}$ sensors at frequency $f$.

$\vec{r}_{i j}=\vec{r}_{j}-\vec{r}_{i}\left(\vec{r}_{i}\right.$ and $\vec{r}_{j}$ are the position vectors of the $i_{t h}$ and $j_{t h}$ sensors $)$.

The wave field has consistence to surface waves propagating. The only unknown in the preceding equation is the phase velocity for each frequency, which can be obtained from the inversion of the observed correlation coefficients, it is possible to invert that phase velocity dispersion curve to obtain a shear-wave velocity profile with standard techniques (Bonnefoy 2004). Frequency-wavenumber (f-k) method is based on the fact that a stationary random process can be characterized by means of a spectral density function, which provides the information concerning the power as a function of frequency (Askari et al. 2004). 


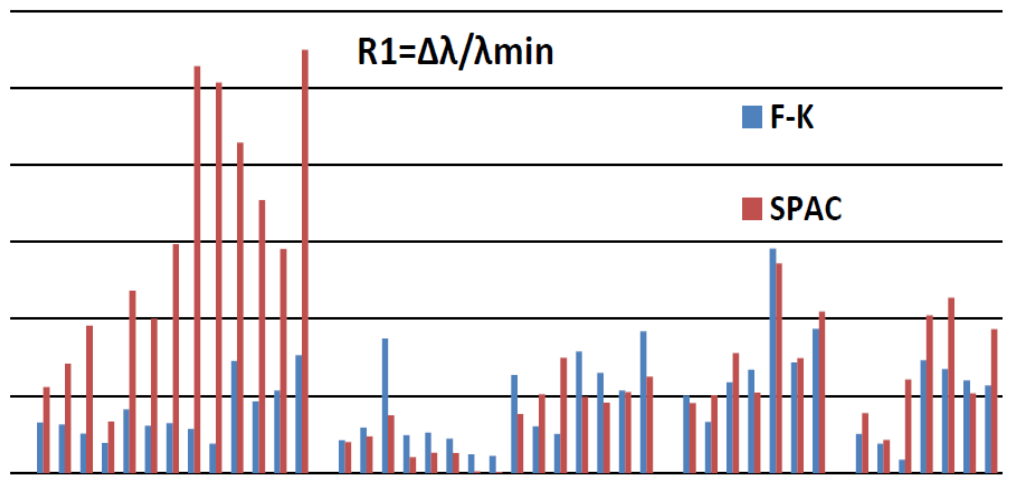

fig 4: R1 amounts for all arrays of Kelarabad site

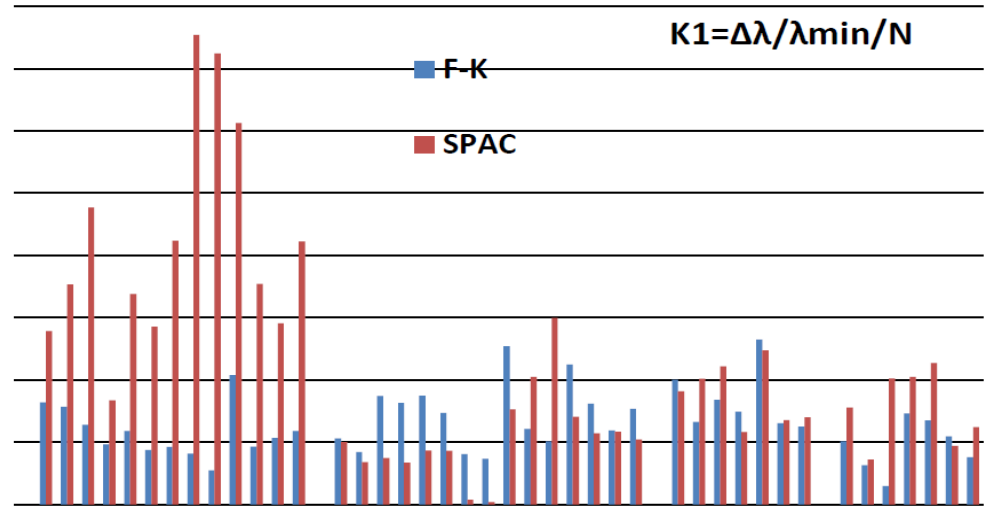

fig 5: K1 amounts for all arrays of Kelarabad site

\section{CONSIDERATIONS}

To find the shear wave profile of subsurface layers, neighbourhood algorithm is used. Different input models were considered for a parametric study. Based on obtained average results from $\mathrm{f}-\mathrm{k}$ processing method, it seemed that Vs profile derived from array A is more consistent with previous site investigation results (Figure 5). The results of E-array (using f-k method) in several available times compared to the reference Vs profile (In- Hole investigations) are presented in Figure 8-a; Also for array A (SPAC) in Figure 8-b. Inversion processing results are shown in figure 6.Obtained $\mathrm{Vs}$ in all areas shown in figure 7.

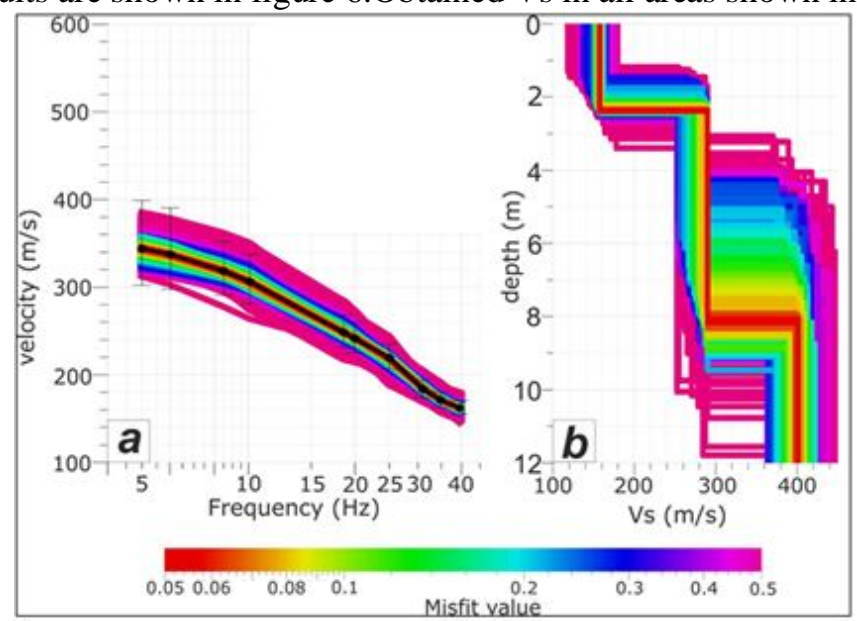

fig 6: the results of inversion processing results:

a) Derived dispersion curve b) Derived Vs for models 


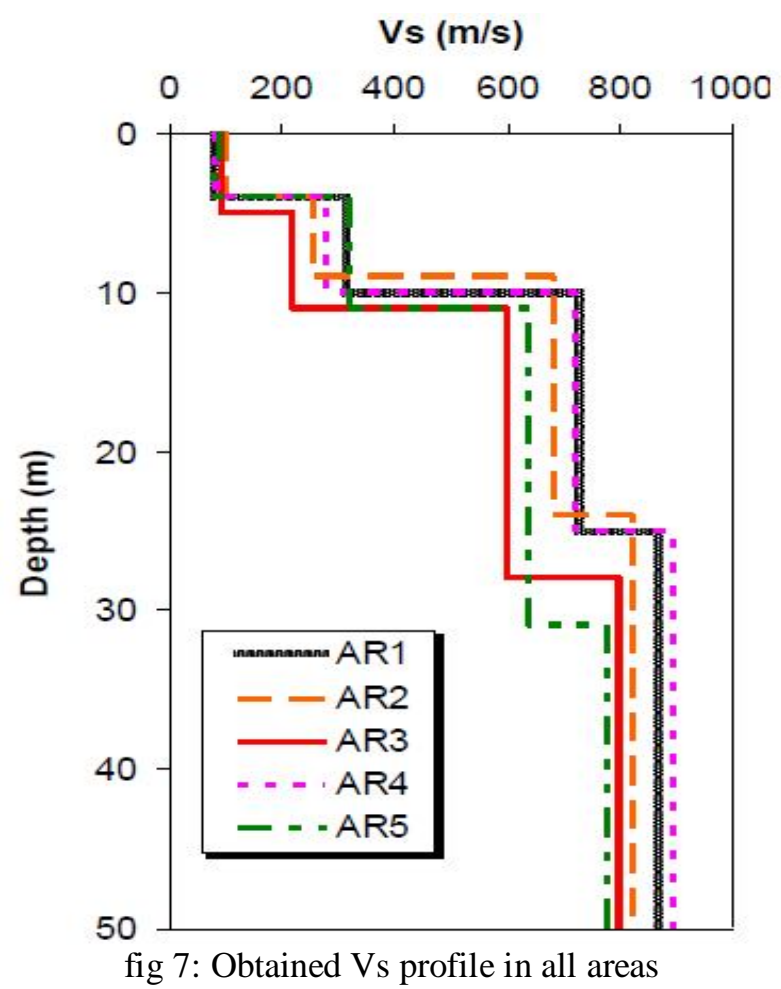

\section{EVALUATING THE PRECISION VALUES}

Figure 8 shows examples of $f$ - $k$ spectra for four different size arrays using the records observed at JEP. The $f$ $k$ spectra are calculated at $51 \times 51$ grid points at each frequency. This figure presents the $f-k$ spectra at $2.73 \mathrm{~Hz}, 1.66 \mathrm{~Hz}, 0.98 \mathrm{~Hz}$ and $0.49 \mathrm{~Hz}$ from the records observed by the M-, L-, X- and D-arrays, respectively. The propagation direction $(\theta)$ is measured clockwise from the north in degrees. We estimate the phase velocity $(V)$ in $\mathrm{km} / \mathrm{sec}$ from the maximum peak in the $f-k$ spectrum.
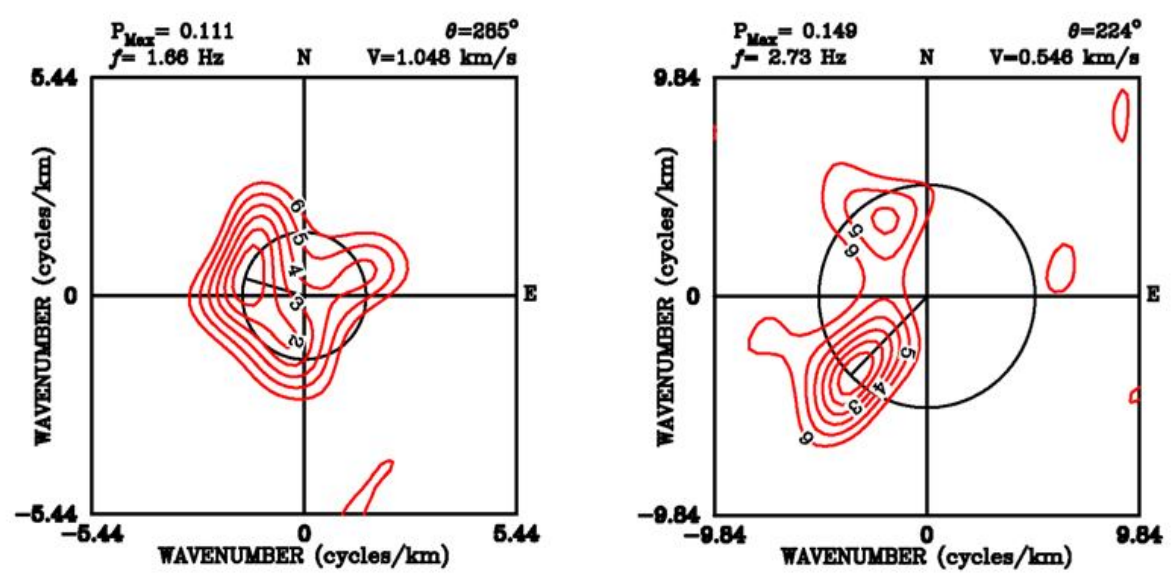

fig 8: f-k spectra plots for frequencies $0.42,0.94,1.66$, and $2.73 \mathrm{~Hz}$ are calculated from microtremors records

\section{RESULTS AND CONCLUSION}

In this paper, 5 arrays were arranged to investigate shear wave velocity profile of deep sedimentary alluvium in Kelarabad site. Ability of mircrotremor array method for describing shear wave velocity of subsurface soil has been considered. First, by using geotechnical drilling, layering and Vs profile of the studied site determined precisely. Later with mounting some seismometers in different array layout including circular and triangular shape, mircrotremor data were recorded in the site and mircrotremor data were processed using conventional $\mathrm{f}-\mathrm{k}$ and SPAC methods and the result compared with direct methods. The results show in the f-k method, estimated Vs values are lower than reference Vs profile of the site but in deeper depth the 
estimated Vs values are larger than reference Vs values. Our method shows better results than Betting (2001).In this method, results are more precise in different frequencies also in comparison with Park (2004). Vs profiles in different times show precision of sensing the depth of layer in the low traffic times was more than high traffic times in the both $\mathrm{f}-\mathrm{k}$ and SPAC methods. Sharp layer changes have been detected in the near of surface ground less than 10 meter Reliability of $\mathrm{f}-\mathrm{k}$ method almost in the all arrays is more than SPAC method.

\section{REFERENCES:}

[1]. Askari, A., Azadi, M., Ghayamghamian, M.R., (2004) "Preliminary Seismic Microzonation of Bam." Journal of Seismology and Earthquake Engineering (JSEE), Vol. 5, No. 4, PP. 69-80.

[2]. Berberian, M., Goreishi, M., Arjang, A. \& Mohajer A., (1985) "Investigating of neoseismotectonics and seismicity and faulting in Tehran", 56th Report, Geological Survey of Iran, Tehran.

[3]. Bettig B., Bard P-Y, Scherbaum F, Riepl J, Cotton F, Cornou C, Hatzfeld D. (2001)“Analysis of dense array noise measurements using the modified spatial auto-correlation method (SPAC): application to the Grenoble area". Bolettino di Geofisica Teorica Applicata; 42(3-4): 281-304.

[4]. Bonnefoy S, Cornou C, Kristek J, Ohrnberger M, Wathelet M, Bard P-Y, Moczo P, Faeh D, Cotton (2004), Simulation of Seismic Ambient Vibrations, $13^{\text {th }}$ World Conference on Earthquake Engineering,Canada.

[5]. Cara F, Di Giulio G, Galluzzo D, Foijtikova L, Maresca R, Moczo P, Rovelli A.(2003) "Predominent frequency variations in the ambient noise recorded in the Colfiorito basin (Umbria, Italy)". European Geophysical Society-American Geophysical Union - European Union of Geophysics Joint Assembly, Nice.

[6]. Cornou C. (2004). "Simulation of seismic ambient noise: I H/V and array techniques of canonical models". Proceedings of the $13^{\text {th }}$ World Conference on Earthquake Engineering, Vancouver, Canada. Paper no. 1120.

[7]. Davoodi M, Haghshenas E, Esfahanizadeh M, Mirjalili M, Atashband S.(2008) Evaluate reliability of f-k and SPAC methods, 14th World Conference on Earthquake Engineering, Englewood Cliffs, New Jersy.

[8]. Gardner, G. F., Gardner, L. W. and Gregory, A. R.,(1994) Formation velocity and density the diagnostic basic for stratigraphic trap, Geophysics, 39, 770-780.

[9]. Nakamura Y. (1989) "A method for dynamic characteristics estimation of subsurface using microtremor on the ground surface". Quaterly Report Railway Tech. Res.; 30(1):25-30.

[10].Nourozi M. (2013), Application of Microtremor for Investigation of Sedimentary Basin Using Cross-Correlation Technique, M.Sc. thesis in IIEES, 2013.

[11].Paolucci, R, (1999) "Shear resonance frequencies of alluvial valleys by Rayleigh's method". Earthquake Spectra; 15(3):503:21.

[12].Park, C. B., Miller, R. D., Laflen D., Neb C., Ivanov, J., Bennett B., and Huggins R. (2004),Imaging dispersion curves of passive surface waves. SEG Expanded Abstracts 23, 1357-1360.

[13].Poormirzaee, R., Hamidzadeh, R. M. and Zarean, A., (1997), Inversion seismic refraction data using particle foundations", Prentice-Hall. 